\title{
The protective role of pycnogenol against oxidative stress induced by feeding young male rats on potato chips
}

\author{
Mamdouh Rashad El-Sawi \\ Zoology Department, Faculty of Science, Mansoura University, Egypt
}

\begin{tabular}{|l|l|}
\hline $\begin{array}{l}\text { Article history } \\
\text { Received: }\end{array}$ & $\begin{array}{l}\text { Abstract } \\
\text { Revised: }\end{array}$ \\
Accepted: & $\begin{array}{l}\text { Oxidative damage is implicated in the pathogenesis of various tissue injuries. In the } \\
\text { present study, the ability of pycnogenol (PYC) as a potent antioxidant to protect potato } \\
\text { chips-induced oxidative stress in both liver and brain of young weaned albino rats was } \\
\text { examined. Four experimental groups of six rats were constructed: control untreated } \\
\text { group; group treated orally } 50 \mathrm{mg} / \mathrm{kg} / \mathrm{day} \text { PYC; group fed on potato chips; and the } \\
\text { group fed on potato chips and treated orally with the same dose of PYC. After 30 days } \\
\text { of treatment, markers of oxidative stress were assessed by measurement of both } \\
\text { malondialdehyde (MDA) and glutathione (GSH) contents and activities of glutathione- } \\
\text { s-transferase (GST), catalase (CAT), and superoxide dismutase (SOD) in both liver } \\
\text { and brain tissue homogenates. Serum total antioxidant capacity (TAC) was also } \\
\text { determined. Feeding rats on potato chips produced a significant increase in MDA } \\
\text { concentration, marked decrease in GSH content and GST activity in both liver and } \\
\text { brain. However, activities of CAT and SOD were significantly declined in the liver } \\
\text { only. Significant decrease in serum TAC of animals fed on potato chips was observed. } \\
\text { Administration of PYC to rats fed on potato chips blocked oxidative stress. In the } \\
\text { liver, PYC prevented an increase in MDA, and decrease in GSH and GST but, it } \\
\text { partially improved the hepatic activity of CAT and SOD. The results indicate that PYC } \\
\text { has a protective effect against potato chips-induced toxicity in rats. } \\
\text { Keywords: Potato chips; acrylamide; Pycnogenol; oxidative stress }\end{array}$
\end{tabular}

To cite this article: El-Sawi, RM 2016. The protective role of pycnogenol against oxidative stress induced by feeding young male rats on potato chips. Res. Opin. Anim. Vet. Sci., 6(7): 194-199.

\section{Introduction}

Oxidative stress occurs when the balance between antioxidants and reactive oxygen species (ROS) are disrupted because of either depletion of antioxidants or accumulation of ROS. It is therefore associated with increased either the production of ROS, such as free radicals and peroxides or a significant decrease in the effectiveness of antioxidant defence, such as glutathione (Birben et al., 2012). As oxidation reactions can produce free radicals, these radicals can start chain reactions in the cell causing damage to this cell. Injuries produced by oxidative stress depend upon its severity (Lennon et al., 1991).

There are many exogenous sources of oxidants, such as chemicals, which can cause oxidative stress. Acrylamide is a chemical which is a potentially toxic and potentially cancer-causing substance that can be naturally present in uncooked, raw foods in very small amounts. The average acrylamide intake for the general population was estimated to be in the range of 0.3- 0.88 $\mu \mathrm{g} / \mathrm{kg} /$ day. Therefore, the presence of acrylamide

*Corresponding author: El-Sawi, Zoology Department, Faculty of Science, Mansoura University, Egypt 
in foodstuffs may be an important risk factor regarding the general population health and also a concern for authorities (Stadler et al., 2002). The highest concentrations of acrylamide have therefore been identified in potato and grain-base foods that are cooked at very high temperatures, e.g. frying, grilling or backing (Tareke et al., 2002).

At high temperature, acrylamide is thought to form in food, principally from the interaction of amino acid asparagine with glucose or other carbohydrates (Surdyk et al., 2004). Acrylamide is easily absorbed by the body through different entry routes: inhalation during cigarette smoking, ingestion with drinking water from flocculent-treated water, and eating potato chips, French fries, and processed cereals; and through skin absorption of cosmetics (Shipp et al., 2006).

It has been reported that acute exposure to acrylamide caused an increase in lipid peroxidation and decrease in glutathoin (GSH) contents and activity of glutathione-s-transferase (GST) in a dose dependent manner in rat liver, while in brain only acrylamide produced a decrease in GSH content (Srivastava et al., 1983). However, in vivo, a single dose of acrylamide depleted GSH content of rat brain in a concentrationdependent manner without inhibiting GST activity. Repeated administration of acrylamide decreased both GSH content and GST activity in the brain (Srivastava et al., 1986).

Acrylamide has significant binding capacity to liver, brain and erythrocytes (Sumner et al., 1997). Teodor et al. (2011) described that acrylamide administration produced liver damage as evidenced by the increased serum activity of transaminases in adult Wistar male rats. Totani et al. (2007) showed that there was a relatively little increase in serum levels of alanine transaminase (ALT) and aspartate transaminase (AST) in rats exposed to acrylamide for 12 weeks. Allam et al. (2010) found that acrylamide increased serum ALT and AST activities. Recently, acrylamide was found to induce oxidative stress in rat and chick embryonic liver as indicated by increasing the rate of lipid peroxidation and suppress activity of the antioxidant enzymes (Venkatasubbaiah et al., 2014).

Medicinal plants and their products have attracted worldwide interest due to the growing recognition of natural products and their potential role in drug discovery. There are many species of medicinal plants which are widely used in the traditional medicine system due to their phototherapeutic properties in treating a variety of diseases (Bellakhdar et al., 1991). The dietary supplement pycnogeno (PYC) is a watersoluble mixture of flavonoid compounds extracted from the bark of maritime pine (Pinus pinaster), its major constituents are polyphenols, flavonoids, and oligomeric procyanidins (Guo et al., 1999). PYC is getting increased attention throughout the world because of its powerful antioxidative action (Lee et al., 2013; Ko et al., 2014). PYC, a potent antioxidant, acts also as a free-radical scavenger, enhances synthesis of antioxidative enzymes and regenerates vitamins $\mathrm{C}$ and E (Rohdewald, 2002). The present work aims to show the role of PYC on oxidative stress caused by acrylamide in rats.

\section{Materials and Methods}

\section{Animal treatments}

Young Wistar male rats, weighing 40-50 g, were housed in metal cages with the floor covered with sawdust. Animals were acclimated for one week pre experimentation in a controlled environment (12 hours light/dark cycle, temperature of $23-25^{\circ} \mathrm{C}$ ) throughout the experimental period. The rats had free access to food, and tap water ad libitum.

Four equal groups, each of six rats were subjected to dosing as follows:

Group 1: control animals which fed normal chewing diet.

Group 2: received PYC, orally, at a dose rate of 50 $\mathrm{mg} / \mathrm{kg} /$ day for 30 days.

Group 3: fed totally on potato chips until satiety, every day for 30 days; other diets were ordinary rodent's food.

Group 4: fed on potato chips and received PYC, as described in groups 2 and 3.

At the end of the treatment period, rats were fasted for 18 hours before collection of blood and tissue samples.

\section{Blood sampling}

Blood samples were collected from the orbital sinus, next to the eyeball, in fine-walled Pasteur pipettes, and the blood samples were left for complete coagulation. Serum was prepared by centrifugation of the blood samples at $800 \times \mathrm{g}$ for 15 minutes. Separated sera were transferred into Eppendorf tubes and kept in a deep freezer at $-20^{\circ} \mathrm{C}$ until performing the biochemical analysis.

\section{Tissue sampling}

Rats were then sacrificed under slight ether anesthesia and dissected. A portion of left lobe of liver and whole brain was quickly removed, washed in $10 \%$ (w/v) buffer solution, weighed and homogenized in cold phosphate buffer solution ( $\mathrm{pH}$ 7.4). Tissue homogenates were centrifuged at $800 \times \mathrm{g}$ for 15 minutes. Separated supernatants were transferred into Eppendorf tubes and kept in a deep freezer at $-20^{\circ} \mathrm{C}$ until performing the biochemical analysis.

\section{Biochemical analysis}

Lipid peroxidation, as a marker of oxidative damage was determined in both liver and brain 
homogenates after Ohkawa et al. (1979). GSH content in liver and brain homogenates were measured by the method of Beutler et al. (1963). Antioxidant enzyme activities in both liver and brain, including GST was determined by the method of Habig et al. (1974), CAT was measured by Aebi (1984) and SOD was evaluated by the procedure described by Nishikimi et al. (1972). TAC in serum was determined by the method of Koracevi et al. (2001).

\section{Statistical analysis}

The values were expressed as the mean \pm SEM for the 06 rats in each group. Differences between groups were assessed by one way analysis of variance (ANOVA) using the statistical package for social sciences (SPSS). Post hoc testing was performed for intergroup comparisons using the least significant difference (LSD) test. A value corresponding to $\mathrm{P}<0.05$ was considered statistically significant.

\section{Results}

As presented in Table 1, oral administration of PYC alone produced no significant changes in hepatic contents of both MDA and GSH as well as in the hepatic activities of antioxidant enzymes GST, CAT, and SOD. However, a marked increase in serum level of TAC $(\mathrm{P}<0.05,+47.83 \%)$ was observed following treatment with $\mathrm{PYC}$ in rats.

Table 1 also shows that young rats fed on potato chips for 30 days indicated increased lipid peroxidation content in the liver as evidenced by significantly enhanced hepatic content of MDA $(\mathrm{P}<0.01,+153.27 \%)$, compared to the obtained results in the control group. In contrast, the GSH concentration in the liver decreased $(\mathrm{P}<0.05,-45.27 \%)$ in the same animal group. Hepatic activities of antioxidant enzymes GST, CAT, and SOD in animals fed on potato chips were significantly decreased $(\mathrm{P}<0.01,-59.56 \% ; \mathrm{P}<0.01,-40.76 \%$ and $\mathrm{P}<0.01,-52.49 \%$ respectively) compared to those in the control group. In addition, there was a marked reduction in serum TAC content $(\mathrm{P}<0.05,-37.39 \%)$.

Obtained results on the protective effect of PYC on the potato chips-induced oxidative stress displayed an inhibitory effect on the process of lipid peroxidation as evidenced by marked reduction in MDA content in the liver compared to control level $(\mathrm{P}<0.05,-44.91 \%$, compared with a group fed on potato chips; $\mathrm{P}>0.05$, +39.51 , comparing with control). PYC prevented the reduction in hepatic content of GSH in young rats fed on potato chips. The hepatic activity of GST in rats treated with PYC and fed on potato chips was significantly increased compared with those fed on potato chips only $(\mathrm{P}<0.05,+81.31 \%)$. However, in comparison with control, obtained a reduction in GST activity in the liver of the same group was not significant $(\mathrm{P}>0.05,-26.68 \%)$. The results showed significantly increased activity of hepatic CAT in animals fed on potato chips and treated with PYC when compared with those fed on potato chips only $(\mathrm{P}<0.01$, $+25.83 \%)$. While, comparing with control, a remarkable decrease in hepatic enzyme activity was observed $(\mathrm{P}<0.05,-25.40 \%)$. PYC treatment in animals fed on potato chips also produced a marked increase in hepatic activity of SOD compared with a group fed on potato chips only $(\mathrm{P}<0.05,+55.95 \%)$. However, activity

Table 1: Liver and serum oxidative stress markers in male young rats of control and different treated groups.

\begin{tabular}{lcccc}
\hline Groups parameters & Control & PYC & Fed on potato chips & PYC + potato chips \\
\hline MDA (nM/g tissue) & $4.73 \pm 2.13$ & $4.70 \pm 1.66(-0.63)$ & $11.98 \pm 4.08^{I b}(+153.27)$ & $6.6 \pm 2.57^{3 a}(39.51,-44.91)$ \\
GSH (mg/g tissue) & $10.36 \pm 1.95$ & $10.22 \pm 2.79(-1.34)$ & $5.67 \pm 2.14^{1 a}(-45.27)$ & $8.44 \pm 5.44(-18.53,48.85)$ \\
GST (U/ g tissue) & $5638.8 \pm 470.7$ & $5573.0 \pm 338.1(-1.17)$ & $2280.5 \pm 112.1^{1 b}(-59.56)$ & $4134.7 \pm 142.3^{3 a}(-26.68,81.31)$ \\
CAT (U/g tissue) & $40.5 \pm 2.53$ & $37.99 \pm 3.46(-6.22)$ & $24.0 \pm 7.71^{1 b}(-40.76)$ & $30.2 \pm 6.11^{l a, 3 b}(-25.40,25.83)$ \\
SOD (U/g tissue) & $2315.2 \pm 146.3$ & $2131.2 \pm 413.02(-7.95)$ & $1100.0 \pm 387.19^{l b}(-52.49)$ & $1715.5 \pm 673.4^{l a ; 3 a}(-25.90,55.95)$ \\
TAC (nM/L) & $1.15 \pm 0.11$ & $1.7 \pm 0.13^{I a}(47.83)$ & $0.72 \pm 0.10^{1 a}(-37.39)$ & $1.71 \pm 0.22^{l a, 3 c}(49.2,137.5)$ \\
\hline
\end{tabular}

Results obtained are given in mean $\pm \mathrm{SE},(n=6)$. Values in parentheses represent percent of changes from control and group fed on potato chips, respectively; ${ }^{1}$ Significantly different from control; ${ }^{3}$ Significantly different from group fed on potato chips; ${ }^{a}<$ $0.05 ;^{b}<0.01 ;{ }^{c}<0.005$.

Table 2: Brain oxidative stress markers in male young rats of control and different treated groups

\begin{tabular}{lcccc}
\hline Groups Parameter & Control & PYC & Fed on potato chips & PYC + potato chips \\
\hline MDA (nM/g tissue) & $18.75 \pm 3.21$ & $18.15 \pm 3.05(-3.17)$ & $29.25 \pm 12.63^{1 b}(56.05)$ & $22.18 \pm 2.37(18.30,24.17)$ \\
GSH (mg/g tissue) & $52.3 \pm 7.87$ & $55.11 \pm 7.18(5.29)$ & $38.3 \pm 15.81^{1 a}(-26.76)$ & $48.66 \pm 5.6(-7.02,27.05)$ \\
GST (U/g tissue) & $6288.2 \pm 487$ & $7770.7 \pm 741.8^{1 a}(23.58)$ & $1786.3 \pm 812.7^{1 b}(-71.60)$ & $2907 \pm 999.8^{1 b ; 3 b}(-53.8,62.7)$ \\
CAT (U/g tissue) & $40.9 \pm 5.41$ & $38.59 \pm 9.0(-5.62)$ & $43.8 \pm 3.70(7.16)$ & $34.77 \pm 11.64(-14.96,-20.6)$ \\
SOD (U/g tissue) & $2761.5 \pm 106$ & $3157.5 \pm 255.9^{1 a}(14.34)$ & $2861.3 \pm 445.0(3.62)$ & $2946 \pm 423.1(6.68,2.96)$ \\
\hline
\end{tabular}

Results obtained are given in mean $\pm \mathrm{SE},(\mathrm{n}=6)$. Values in parentheses represent percent of changes from control and group fed on potato chips, respectively; ${ }^{1}$ Significantly different from control; ${ }^{3}$ Significantly different from group fed on potato chips; ${ }^{a}<$ $0.05 ;^{b}<0.01 ;{ }^{c}<0.005$. 
of hepatic SOD of this group appeared a decrease significantly when compared with control $(\mathrm{P}<0.05$, $25.90 \%$ ). Serum level of TAC was significantly enhanced in rats fed on potato chips and treated with PYC when compared with those fed on potato chips only $(\mathrm{P}<0.005,+137.5 \%)$. Interestingly, the result of this group showed significantly increased serum level of TAC compared with control $(\mathrm{P}<0.05,+49.2 \%)$.

As presented in Table 2, oral administration of PYC alone in a dose of $50 \mathrm{mg} / \mathrm{kg} / \mathrm{day}$ produced no significant changes in brain contents of both MDA and GSH as well as CAT in the brain. However, marked increases in brain GST and SOD activities $(\mathrm{P}<0.05$, $+23.58 \%$ and $\mathrm{P}<0.05,14.34 \%$, respectively) were observed following treatment with PYC in rats.

Table 2 also shows that young rats fed on potato chips in the breakfast meal for 30 days show increased content in lipid peroxidation in the brain, as evidenced by the significantly enhanced brain content of MDA $(\mathrm{P}<0.01,+56.05 \%)$, compared to obtain results in the control group. In contrast, GSH concentration was decreased significantly $(\mathrm{P}<0.05,-26.76 \%)$ in the same animal group. Brain activity of antioxidant enzymes CAT and SOD in animals fed on potato chips were in normal levels ( $\mathrm{P}>0.05,7.16 \%$ and $\mathrm{P}>0.05,3.62 \%$, respectively) whereas, GST activity was significantly decreased $(\mathrm{P}<0.01,-71.60)$ compared to those in the control group.

Obtained results on the protective effect of PYC on the potato chips-induced oxidative stress displayed an inhibitory effect on the process of lipid peroxidation as evidenced by a marked reduction in the production of MDA in the brain to the control level $(\mathrm{P}<0.05$, $24.17 \%$, compared with a group fed on potato chips; $\mathrm{P}>0.05,18.3$, comparing with control). PYC largely prevented the reduction in brain content of GSH in young rats fed on potato chips ( $\mathrm{P}>0.05,27.04 \%$, compared with a group fed on potato chips; $\mathrm{P}>0.05$, $7.02 \%$, comparing with control). The brain activity of GST in rats treated with PYC and fed on potato chips was significantly increased compared with those fed on potato chips alone $(\mathrm{P}<0.05,+62.73 \%)$. However, in comparison with control, obtained a reduction in GST activity of the same group was significantly different from control $(\mathrm{P}<0.05,-53.77 \%)$. The results showed an insignificant decrease in brain CAT activity and an insignificant increase in SOD activity in animals fed on potato chips and treated with PYC when compared either with those fed on potato chips only or with control.

\section{Discussion}

Imbalance between oxidants produced in the body, such as reactive oxygen species (ROS) as well as reactive nitrogen species (RNS) and the levels of defense mechanism components of the body against oxidation in favor of oxidants leads to a state of oxidative stress, which have the potential to cause tissue damage (Sies et al., 1985). Oxidative stress is one of the most important effects of the toxicity of acrylamide; which causes oxidative stress by working to generate ROS that contribute to reducing the body's ability against oxidation and enhances the production of lipid peroxidation (LPO) (Kojic et al., 1989, Lebda et al., 2015).

In the present study, young rats feeding on fried potato slices (in breakfast meal only until satiety) for 30 consequent days, showed an increase in the level of LPO in the liver and brain tissue homogenates as well as the diminishing of the GSH and decrease in the activities of the enzymes SOD, CAT and GST in addition to the significant deficiency in the serum TAC. The results obtained regarding high significant content of MDA and the diminishing in the level of glutathione has approved studies conducted by Khan et al. (2011) and Kadry (2012).

The increase in the MDA may be attributed to the fact that acrylamide can generate ROS that promote the production of lipid peroxides which are then produce MDA. While the decrease of GSH in these tissues due to it exhausted in the neutralization of ROS generated by acrylamides (Lee and Jacops, 2005) or by direct interaction between the acrylamides and GSH, where the GSH lose a thiol group (-SH) in the presence of acrylamide (Tong et al., 2004).

The results obtained corresponding to the low activity of enzymes SOD, CAT, as well as GST in potato chips eating rats, come parallel with the results of other studies conducted by Zhu et al. (2008) and Khan et al. (2011) for SOD in both brain and liver tissue and Kadry (2012) for SOD in the brain tissue and Khan et al. (2011) for the CAT activity in the liver tissue homogenate.

As for the enzymatic activity of GST, the results of the current study were compatible with the study of each of Srivastava et al. (1986) in the brain, Khan et al. (2011) in the liver and Taha et al. (2013) in the liver and brain tissue. Disturbances in the normal redox state by ACY can cause toxic effects through the production of cell damaging peroxides and free radicals. A decline in serum TAC coincided with the results obtained by Tozan-Beceren et al. (2012).

The results of the current study showed that the treated rats fed on fried potato slices with PYC have improved the levels of MDA and the GSH as well as the activity of antioxidant enzymes; SOD, CAT and GST and the results agree with other studies conducted by Parveen et al. (2013) on the liver tissue of male Wistar rats and Edrees et al. (2009) on male albino rats for GSH, SOD, CAT and MDA.

Defense mechanisms against oxidation are mainly dependent on capturing or disabling the ROS before the events of the case of oxidative stress by GSH, SOD and 
GSH-Px that capture the superoxide anion (O2 - -) and hydrogen peroxide $\mathrm{H}_{2} \mathrm{O}_{2}$ at low concentrations, and by the CAT, which capture the $\mathrm{H}_{2} \mathrm{O}_{2}$ at high concentration as a secondary defense mechanism to prevent any damage (Girotti, 1990), the PYC improves enzymatic and non-enzymatic antioxidants to near normal levels in the body in the group of animals treated with PYC coincided with feeding on the fried potato slices that contains a proportion of acrylamide indicates that PYC is very effective against the oxidation process.

It seems that PYC can inhibit LPO by reducing the level of MDA within the body, removing free radicals, especially hydroxyl $(\mathrm{OH} \bullet)$ and superoxide anion $\left(\mathrm{O}_{2} \bullet-\right)$ and the organization of the surplus of nitric oxide (NO•) (Paker et al., 1999; Maritim et al., 2003).

The increase in the content of GSH as well as the activity of GST, CAT and SOD, which led to a rise in the total capacity of antioxidants as a result of treatment with PYC, may be due to the ability of PYC to stimulate cell components for the production of most of the antioxidants in addition to doubling the cell's production of the SOD, CAT and GSH which represent the strongest weapon to disable free radicals (ErbenBayeta et al., 2000).

\section{Conclusion}

The results of the current study showed that the treatment of young rats with PYC plays a role in protecting the young rats from adverse effects caused by acrylamide, made most of the standards to swing on the normal level and indicates that PYC stimulates the production of the antioxidants and scavenge free radicals.

\section{References}

Aebi H (1984) Catalase in vitro. Methods Enzymol 105: 121-126.

Allam AA, El-Ghareeb AW, Abdul-Hamid M, Bakery AE, Gad M, Sabri M (2010) Effect of prenatal and perinatal acrylamide on the biochemical and morphological changes in liver of developing albino rat. Arch Toxicol 84: 129-141.

Bellakhdar J, Claisse R, Fleurentin J, Younos C (1991) Repertory of standard herbal drugs in the Moroccan pharmacopoea. J Ethnopharmacol 35(2):123-143.

Beutler E, Durgun O, Kelly BM (1963) Improved method for the determination of blood glutathione. J Lab Clin Med 51: 882-888.

Birben E, Sahiner UM, Cansin SC, Erzurum S, Kalayci O (2012) Oxidative Stress and Antioxidant Defense. WAO J 5: 9-19.

Edrees G, EI-Sawi M, El-Harty M (2009) Antioxidant defense of pycnogenol against glycerol induced acute renal failure in mice. The EJHM 34: 1-8.
Erben-Bayeta, MS, Benjamin HS, Lau, MD (2000) Pycnogenol inhibits generation of inflammatory mediators in macrophages. Nutr Res 20(2): 249259.

Girotii A. (1990) Photodynamic lipid peroxidation in biology systems. J Photochem Photobiol 51(4): 497-509.

Guo Q, Zhao B, Packer L (1999) Electron spin resonance study of free radicals formed from a procyanidin-rich pine (Pinus maritima) bark extract, pycnogenol. Free Radic Biol Med 27(1112): 1308-1312.

Habig WH, Pabst MJ, Jakoby WB (1974) GlutathioneS-transferases. The first enzymatic step in mercapturic acid formation. J Biol Chem 249 (22): 7130-7139.

Kadry MS (2012) Antioxidant and immunostimulant effect of Carica Papaya aqueous extract in acrylamide intoxicated rats. Nat and Sci 10(3): 16-22.

Khan RM, Afzaal M, Saeed N, Shabbir M (2011) Protective potential of methanol extract of Digera muricata on acrylamide induced hepatotoxicity in rats. Afr J Bio 10(42): 8456-8464.

Ko J, Lee I, Park S, Moon C, Kang S, Kim S, Kim J (2014) Protective effects of pine bark extract against cisplatin-induced hepatotoxicity and oxidative stress in rats. Lab Anim Res 30: 174-180.

Kojic G, Vlahonic P, Ravloure D, Talwwar GP, Srivastave LM, Mudgil KP (1989) Possible importance of the cation binding site for the oxidative modification of liver nucleosidase. Arch Physiol Biochem 106: 91-99.

Koracevic D, Koracevic G, Djordjevic, V, Andrejevic S, Cosic V (2001) Method for the measurement of antioxidant activity in human fluids. J Clin Pathol 54(5): 356-361.

Lebda MA, Gad SB, Rashed RR (2015) The effect of lipoic acid on acrylamide-induced neuropathy in rats with reference to biochemical, hematological, and behavioral alterations. Pharm Biol 53(8): 1207-1213.

Lee DH, Jacobs DR (2005) Association between serum $\gamma$-glutamyl transferases and C-reactive protein. Atherosclerosis 178: 327- 330.

Lee M, Moon K, Bae D, Park M, Jang A (2013) The effects of pycnogenol on antioxidant enzymes in a mouse model of ozone exposure. Korean J Intern Med 28(2): 216-223.

Lennon SV, Martin SJ, Cotter TG (1991) Dosedependent induction of apoptosis in human tumor cell lines by widely diverging stimuli. Cell Prolif 24(2): 203-14).

Maritim AC, Sanders RA, Watkins JB (2003) Diabetes, oxidative stress, and antioxidants: a review. J Biochem Mol Toxicol 17(1): 24-38. 
Nishikimi M, Appaji N, Yagi K (1972) The occurrence of superoxide anion in the reaction of reduced phenazine methosulfate and molecular oxygen. Biochem Biophys Res Commun 46(2): 849-854.

Ohkawa H, Ohishi N, Yagi K (1979) Assay for lipid peroxides in animal tissues by thiobarbituric acid reaction. Anal Biochem 95: 351-358.

Packer L, Rimbach G, Virgili F (1999) Antioxidant activity and biologic properties of a procyanidinrich extract from pine (Pinus maritime) bark, Pycnogenol Free Rad Biol Med 27 (5-6): 704724.

Parveen K, Ishrat T, Malik S, Kausar MA, Siddiqui WA (2013) Modulatory effects of Pycnogenol in a rat model of insulin-dependent diabetes mellitus: biochemical, histological, and immunohistochemical evidences. Protoplasma 250 (1):347-60.

Rohdewald P (2002) A review of the French maritime pine bark extract (Pycnogenol), a herbal medication with a diverse clinical pharmacology. Int J Clin Pharmacol Ther 40 (4):158-168.

Seth PK (1986) Effect of single and repeated doses of acrylamide and bis-acrylamide on glutathione-Stransferase and dopamine receptors in rat brain. Brain Res 371(2): 319-323.

Shipp A, Lawrence G, Gentry R, McDonald T, Bartow H, Bounds J, Macdonald N, Clewell H, Allen B, Van Landingham C (2006) Acrylamide: review of toxicity data and dose-response analyses for cancer and noncancer effects. Crit Rev Toxicol 36: 481-608.

Sies H (1985) Oxidative stress. Introductory remarks in oxidative stress. Academic Press, London pp: 1-8.

Srivastava SP, Das M, Seth PK (1983) Enhancement of lipid peroxidation in rat liver on acute exposure to styrene and acrylamide a consequence of glutathione depletion. Chem Biol Interact 45(3): 373-380.

Stadler RH, Blank I, Varga N, Robert F, Hau J, Guy PA, Robert M, Riediker S (2002) Acrylamide from Maillard reaction products. Nature 419: 449450.

Sumner SC, Selvaraj L, Nauhaus SK, Fennell TR (1997) Urinary metabolites from F344 rats and B6c3F1 mice co administered acrylamide and acrylonitrile for 1 or 5 days. Chem Res Toxicol 10: 1152-1160.

Surdyk N, Rosen J, Andersson RC, Aman P (2004) Effect of asparagine, fructose, and backing conditions on acrylamide content in yeast- leavened wheat bread. J Agric food Chem 52: 2047-2051.

Taha N, Korshom M, Mandour AW, Sadek K (2013) Effects of garlic and acrylamide on some antioxidant enzymes. Global J Med Plant Res 1(2): 190-194.

Tareke E, Rydberg P, Karlsson P (2002) Analysis of acrylamide, a carcinogen formed in heated foodstuffs. J Agric Food Chem 50: 4998-5006.

Teodor V, Cuciureanu M, Slencu BG, Zamosteanu N, Cuciureanu R (2011) Potential protective role of selenium in acrylamide Intoxication. A biochemical study. Studia Universitatis Vasile Goldis, Seria Stiintele Vietii 21(2): 263-268.

Tong GC, Cornwell WK, Means GE (2004) Reactions of acrylamide with glutathione and serum albumin. Toxicol Lett 147: 127-131.

Totani N, Yawata M, Ojiri Y, Fujioka Y (2007) Effects of trace acrylamide intake in Wistar rats. $\mathrm{J}$ Oleo Sci 56: 501-506.

Tozan-Beceren A, Özer ŞA, Mel Eksioglu-Demiralp E, Şener G, Zehra OG (2012) Melatonin protects against acrylamide induced oxidative tissue damage in rats. Marmara Pharm J 16: 213-21.

Venkatasubbaiah K, Venkataswamy M, Sandhya D, Suresh K Rao KJ (2014) Acrylamide induced oxidative stress in rat and chick embryonic liver tissues. IAJPR 4(6): 2791-2798.

Zhu YJ, Zeng T, Zhu YB, Yu SF, Wang Q S, Zhang LP, Gou X, Xie KQ (2008) Effects of acrylamide on the nervous tissue antioxidant system and sciatic nerve electrophysiology in the rats. Neuro Chem Res 33(11): 2310-17. 